\title{
Human factor in emergency occurrence at NPP during the pandemic COVID-19: new potential risks and recommendations to minimize them
}

\author{
Oleksandr Popov ${ }^{1,2,3}$, Anna Iatsyshyn ${ }^{1, *}$, Norbert Molitor ${ }^{4}$, Andrii Iatsyshyn ${ }^{1,2}$, Yevhen Romanenko ${ }^{3,5}$, Iryna Deinega ${ }^{5}$ \\ Petr Sharov 6 , and Gabriel Mnayarji ${ }^{7}$ \\ ${ }^{1}$ State Institution "The Institute of Environmental Geochemistry of National Academy of Sciences of Ukraine", \\ Department of environmental protection technologies and radiation safety, 34a Palladin Ave., Kyiv, 03142, Ukraine \\ ${ }^{2}$ G.E. Pukhov Institute for Modelling in Energy Engineering of NAS of Ukraine, Department of Mathematical and Econometric \\ Modeling, 15 General Naumova Str., Kyiv, 03164, Ukraine \\ ${ }^{3}$ Interregional Academy of Personnel Management, 2 Frometivska Str., Kyiv, 03039, Ukraine \\ ${ }^{4}$ PLEJADES GmbH - Independent Experts, Feldstr. 5 D-64347, Griesheim, Germany \\ ${ }^{5}$ National Aviation University, 1 Liubomyra Huzara Ave., Kyiv, 03058, Ukraine \\ ${ }^{6}$ Pure Earth, 475 Riverside Drive, Suite 860, New York, NY 10115, United States of America \\ ${ }^{7}$ Pegasus Environmental and Nuclear Services, Inc, Orlando, FL 32819, United States of America
}

\begin{abstract}
COVID-19 pandemic is an emergency that spread across the planet. It threatens lives and health of the population, with many dead and injured. Also, during pandemic there was (and continues to be) a violation of normal living conditions, significant material damage to economies of different countries. Quarantine restrictions affected social, educational, cultural and spiritual spheres of society. There is an urgent threat to operation of critical infrastructure as the pandemic led to large numbers of hospitalized or selfisolated people and being treated at home. At present, the operation of critical infrastructure, and in particular nuclear power plants, is strategically important for the proper functioning of any country. Also, the research describes causes of emergencies at nuclear power plants and identifies another factor - the mass disease of NPP personnel or their relatives on COVID-19. It is determined that timely detection and appropriate work to restore mental health during the pandemic is no less important area of work along with providing medical care to population. Stress associated with uncertainty, threat to health, can have negative consequences for well-being and mental health of workers. Depression, emotional exhaustion, anxiety, irritability, suicidal thoughts, etc. can also be consequences. Socio-psychological support especially for critical infrastructure workers is important to promote mental health during COVID-19 pandemic. Recommendations for sociopsychological support of NPP personnel were developed. Specialized mobile applications are described as convenient and economical way for primary psychological care.
\end{abstract}

\section{Introduction}

COVID-19 spread around the world. It is not only health problem, but it also affects the world economy and the environment in various ways. Although COVID-19 causes serious damage to society but environment state is improved as pollution decreased significantly. COVID-19 imposed restrictions on the movement of people and vehicles in various countries and suspended some industrial activities. Thus, emissions of greenhouse gases, nitrogen dioxide, carbon, etc. decreased. However, COVID-19 also has negative consequences for environment due to large amount of household and medical waste $[1,2,3]$.

COVID-19 and the quarantine restrictions caused by it became an emergency situation that significantly affected well-being of people, families, communities. People experience such situations in different ways, someone without visible violation of ability to function at work or in a close relationship. That is, such people recover quickly, using their own strength. Others need only basic support to improve their well-being. And in the third, there are mental health problems (or the same problems that existed before) that require specialized psychological support. Therefore, response to emergencies is significantly different in each case, as each person experience the same event differently and has different resources and opportunities to recover [4].

Indeed, the pandemic is a challenge not only to physical health but also to mental health. The SecretaryGeneral of the United Nations called on governments to address mental health needs of the coronavirus pandemic immediately, warning that COVID-19 could provoke crisis in this area. An important area for strengthening of mental health strategy during COVID-19 outbreak is psychological support of population, especially health

\footnotetext{
* Corresponding author: anna13.00.10@gmail.com
} 
workers. Stress associated with uncertainty, threat to health, can have negative consequences for well-being and mental health of employees, and can result in depression, emotional exhaustion, and anxiety. Therefore, recovery of mental health and psychosocial aspects during outbreak of COVID-19 are extremely relevant and require special research [5].

COVID-19 disease made many significant changes in activities of various enterprises and organizations, many employees were transferred to remote mode using digital technologies. However, there are enterprises, especially of critical infrastructure (nuclear power plants, thermal power plants, chemical facilities, etc.), where it is impossible to perform official duties remotely and you need to be in the workplace. Critical infrastructure facilities can include enterprises, institutions and organizations, regardless of ownership, which: operate and provide services in the energy sector, chemical, transport, information and communication technologies, electronic communications, banking and financial sectors; provide services in areas of life support of the population, in particular in areas of centralized water supply, sewerage, electricity and gas supply, food production, agriculture, health care; communal, emergency and rescue services, emergency services; included in the list of enterprises of strategic importance for the economy and safety of the state; objects of potentially dangerous technologies and productions.

Today in Ukraine there is developed nuclear energy industry. Its operation is provided by 4 operating nuclear power plants (NPPs): Zaporizhzhya NPP, Rivne NPP, South-Ukraine NPP and Khmelnytska NPP. They are objects of increased danger $[6,7]$, and therefore issue of their safe operation, civil protection of population and environment on the territory of the station is always relevant.

In Ukraine, NPPs consistently provide more than half of electricity production, which is important for economic and social development of the country and compliance with international obligations. In [6] it is noted that experience of NPP operation shows that causes of accidents and incidents are somehow related to behavior of people (human factor), namely - with their attitude to safety problems. Therefore, the focus of NPP management is, first of all, human resources, style and management methods. An important issue for the NNEGC "Energoatom" is to maintain health of its employees at the appropriate level and timely detection of diseases. This is especially important given that work of nuclear workers is associated with increased hazards, including radiation. To preserve the health and efficiency of NNEGC "Energoatom" NPP personnel, conducts constant explanatory work among the personnel about vital need to take care of one's own health, to objectively assess condition of well-being, timely treatment by doctor. In the NNEGC "Energoatom" units where highrisk work is performed, mechanisms of psychophysiological examination of employees are used. Psychophysiological examination is carried out in order to: ensure safety, reliability and efficiency of NPP operation through optimization of personnel; reduction of labor losses and accident prevention; selection of persons who, by the state of professionally important psychophysiological qualities, are able to master the profession and perform their duties effectively; working life of staff.

Monitoring of the psychophysiological condition of NPP employees is carried out during initial and periodic medical examinations. It does not reveal current situation of possible accumulation of fatigue and distress. Also, psychological climate controlin the teams is rare. Its constant implementation (taking into account recommendations of experts in psychophysiological laboratories of nuclear industry) will predict occurrence and influence of distress factors, as emphasized in the publication [7].

In 2020 for the first time unprecedented phenomenon of voluntary social isolation emerged as a way to effectively combat spread of COVID-19 virus. Following recommendations of the World Health Organization the most governments introduced quarantine measures. They severely restricted movement of citizens and effectively led to their self-isolation. Public, social, professional, scientific, religious life of people changed emphasis towards online presence. An integral part of the current quarantine is the Internet, mobile communications, Smartphone, social networks and other digital technologies [5].

Therefore, number of problems need new understanding and research: professional activities of staff during the pandemic; human mental health; training of workers during the pandemic; social and psychological support of population and especially staff of critical infrastructure during the pandemic, etc.

\section{Analysis of previous publications}

Various aspects of software and hardware development for impact assessing of potentially dangerous objects on the environment are described in [8-30]. Features of prevention, occurrence and liquidation of emergencies, in particular at NPPs are considered in publications [7-43]. Provision of psychological support and assistance to victims in emergencies is described in the researches [4, 5, 44-49]. The use of digital technologies for psychological support of personality is considered in publications [50-55]. However, it is important to study impact of COVID-19 on emergencies at Ukrainian NPPs, psycho-traumatization of population during the pandemic and the search for tools and recommendations for sociopsychological support of population and NPP personnel.

The research aim - is to investigate new challenges of emergencies risk increasing at Ukrainian NPPs as result of the human factor during COVID-19 pandemic and to develop recommendations for their minimization.

\section{The research results}

\subsection{Pandemic caused by COVID-19 as emergency}

Every day there are various emergencies in different parts of the world: floods, earthquakes, landslides, hurricanes, 
dust storms, accidents, catastrophes and other natural disasters. In the beginning of 2020 the World Health Organization declared health emergency of international importance. And a pandemic was declared in early March. The pandemic caused by COVID-19 and quarantine restrictions also caused global socio-economic problems.

In the scientific literature [4] "emergencies" are understood as events that go beyond the ordinary life of man and pose a threat to their physical and mental integrity, lead to destruction of social structure of communities and social order. Such situations usually arise as result of accidents, catastrophes, natural disasters, terrorist acts, armed conflicts, epidemics, and others. Emergencies can spread to different scales in covered area, number of victims and so on. The Civil Protection Code of Ukraine [56] states that "an emergency situation is a situation on separate territory or a water body which is characterized by violation of normal living conditions caused by catastrophe, accident, fire, natural disaster, epidemic, epizootic, epiphytosis, use of means of destruction or other dangerous event that led (can lead) to threat to life or health of the population, large number of dead and injured, significant material damage, as well as impossibility of living in such territory or object, conducting economic activity on it. Also, victims of an emergency are people whose health was damaged in result of emergency.

In $[56,57]$ the classification of emergencies is given: 1) emergencies are classified by the nature of origin, degree of distribution, amount of human losses and material damage; 2 ) depending on nature of events origin types of emergencies are determined: (man-made nature; natural nature; social; military); 3) the following levels of emergency situations are determined depending on the consequences extent caused by emergency situation, amount of technical and material resources necessary for their elimination: state; regional; local; object; 4) classification of emergencies according to their levels is established by the Cabinet of Ministers of Ukraine [56].

The study [1] noted that level of air pollution is one of the important indicators that affects the transmission of COVID-19 and mortality. Therefore, COVID-19 can affect environmental factors and vice versa. Critical review of research of relationship between COVID-19 and the environment can formulate a current state of knowledge and guidance for further research. Critical analysis of scientific publications was conducted and 57 articles on interaction between COVID-19 and the environment were selected. Four research clusters were identified (Fig. 1): 1) COVID-19 and environmental degradation; 2) COVID-19 and air pollution, 3) COVID19 and climate/metrological factors; 4) COVID-19 and temperature. The impact of COVID-19 on the environment and impact of environmental indicators on transmission of COVID-19 are considered. It is concluded that COVID-19 pandemic improved environment quality. During pandemic and quarantine restrictions imposed by the governments of different countries led to significant reduction in environmental pollution and improved environmental quality. There is a sharp reduction in carbon emissions, reduced air pollution, reduced noise pollution and beach pollution. Various environmental factors contributed to both spread and reduction of COVID-19 transmission [1].

Collective work [58] emphasizes that COVID-19 pandemic and its consequences can be rehearsal for fight against climate change in the future. The pros and cons of COVID-19 in terms of environmental impact were identified: improving air quality, improving surface water quality, reducing noise pollution and greenhouse gas emissions.

Humans, their life, health and safety are recognized in Ukraine as the highest social value. Geographical environment is the natural basis of her life [59,60]. Mankind has extensive knowledge in the fields of geography, physics, chemistry, biology, and others, actively uses them in social production at the present stage of its development. At the same time it still remains dependent on natural manifestations of the nature forces. Processes that are beyond human control and are related to the life cycle of our planet and influence of external factors can cause emergencies of various kinds. Danger to humanity can be hidden in man-made objects and processes in addition to forces of natural origin: enterprises of various sectors of economy and technological processes, critical infrastructure, defense facilities, etc. Nuclear energy, use of electricity and heat, circulation of hazardous substances cause potential danger of emergencies. They are commonly called manmade [61].

Large proportion of industrial enterprises is potentially dangerous objects associated with the production, storage, transportation and processing of hazardous substances on the territory of Ukraine. Manmade emergencies risk at such enterprises is extremely high as the level of equipment wear in most enterprises is approaching critical. Accidents at such facilities are usually accompanied by environment pollution with toxic substances as well as fires and explosions [59].

People affected by emergencies can need medical care, psychological, material, legal assistance, social and information services, etc. [4]. Emergencies can lead to human casualties, damage to human health, significant material loss and disruption to people's living conditions. They can cause mental and psychological trauma to victims or their relatives and friends.

\subsection{Causes of emergencies at nuclear power plants: domestic and foreign experience}

Scientists in the publication [7] emphasizes that various negative circumstances (infringement processes, safety and mode of operation, natural disasters, technological accidents and incidents of sabotage terrorist purposes, fighting, etc.) at the plant can lead to different emergencies that pose a significant risk to environment, health of personnel and surrounding areas population. It is determined the nature of the action, the scale of destruction of buildings, the size of the material and economic losses by carrying out an analysis of emergency situation on the threat to human life. The most dangerous are emergencies that cause radioactive and chemical pollution. Confirmation of this are tragic experience of 
accidents at the Three Mile Island NPP (USA, 1979), Chornobyl (Ukraine, 1986), Fukushima-1 (Japan, 2011). Such emergencies can lead to significant radioactive contamination, cause significant damage to public health, natural and agroecological systems, etc.

In Ukraine, various normative documents emphasize importance of population protecting from emergencies.

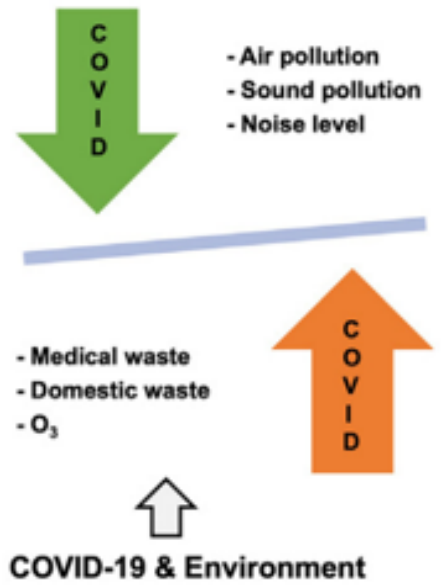

The source [56] states that "civil protection is a function of the state aimed at protecting population, territories, environment and property from emergencies by preventing such situations, eliminating their consequences and providing assistance to victims in peacetime and in special periods".

\section{Environment \& COVID-19}

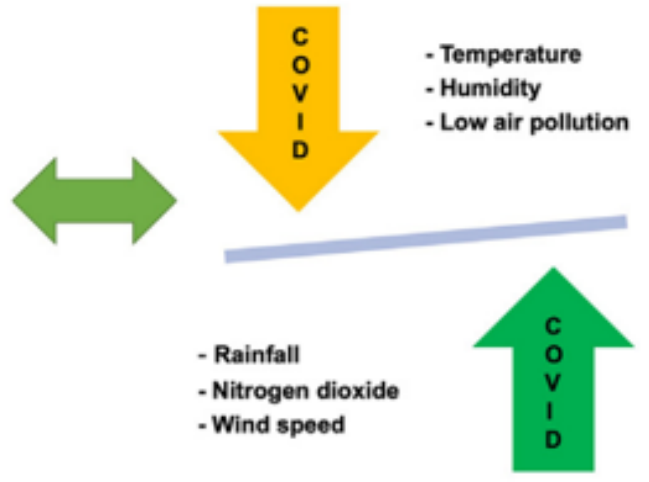

Fig. 1. Interaction of COVID-19 and environment (4 research clusters) [1].

Nuclear safety is ensured by consistent implementation of 5 defense levels in depth strategy. Implementation of measures last defense in depth - the fifth and, partly, in the fourth - in support of measures designed accident management. It is provided by system of emergency preparedness and response NNEGC "Energoatom" in accident and emergency at the plant. Important state task is to mitigate or prevent action of various factors and minimize accidents risk at nuclear power plants, as these stations are economically justified and necessary for normal development of industry, but only if the technical level of nuclear and radiation safety of nuclear power plants is provided [7].

Currently, Ukraine's nuclear energy sector is supplied by 4 operating nuclear power plants: Zaporizhzhya, Rivne, Khmelnytska and South-Ukraine. Analysis of violations at NPPs is carried out in accordance with industry standard "ND 306.2.100-2004 - Regulations on procedure for investigation and accounting of violations in operation of nuclear power plants". It is developed in accordance with international requirements. Work of investigating and accounting for violations in operation of nuclear power plants is very important for safety. This is an element of safety culture. Investigation and accounting of NPP operational events are part of professional culture of nuclear industry with its first steps [62].

Operation of NPPs of Ukraine is carried out in accordance with legal requirements. Their main purposes are: protection of health from possible damage associated with irradiation with sources of ionizing radiation; safe operation of NPPs; environment protection. NPP meets safety requirements when its radiation exposure does not exceed the limits prescribed dose irradiation plant personnel and the public, as well regulations on gasaerosol emissions and liquid discharges, content of radioactive substances in the environment. NNEGC
"Energoatom", NPPs and other separate units within it fully comply with requirements of nuclear and civil protection legislation - in terms of their obligations and responsibilities for development and implementation of emergency preparedness and response measures, civil protection [43].

According to experts from the World Association of NPP Operators, NNEGC "Energoatom" occupies a worthy place in the global nuclear community in terms of nuclear safety and organization of safety culture. Each Ukrainian NPP has examples of positive practices on safety culture. It corresponds to the best world experience, gained during implementation of international projects, etc. The company supports and encourages formation of safety culture among its employees and employees of other organizations that perform work for the NPP. The Council of nuclear safety culture was created in order to determine goals, objectives, optimize implementation of safety culture principles in the operation of Ukrainian NPPs exchange experience, assess the current level of safety culture at NPPs, as well as to review, approve and further monitor the implementation of specific actions of the NPP and the Company as a whole [6].

National emergency prevention organizations, together with research institutes, conduct joint research to increase Europe's preparedness to respond any radiation pollution caused by an emergency or long-term pollution, as part of the joint European EURANOS project. Threat of potentially dangerous situations remains even taking into account improvement of emergency preparedness and response systems emergency situations, the use of automated systems for monitoring technological parameters and the radiation situation at nuclear power plants [7].

Causes of emergencies at nuclear power plants [7]: violation of technological processes; violation of safety 
and operating conditions; natural phenomena and manmade accidents and incidents; fighting; sabotage for terrorist purposes. Small amount of news and events that take place at the nuclear fuel cycle facilities are posted on the site [63]. Also, more detailed information on nuclear and radiation events can be found in the IAEA Unified System for Information Exchange in Incidents and Emergencies.

Based on the analysis of scientific sources and specialized sites [7, 41, 43, 63] we will describe the occurred incidents at various nuclear power plants over the past few years. They were officially reported to the public.

1) in December 2015 at the Leningrad NPP (Russia) there was an accident at the second power unit. Pipeline burst in the turbine hall and the radioactive steam in it filled the room and spread outside the power plant. Cloud of radioactive release reached the territories of Estonia and Finland;

2) in January 2017 power supply of substation and the first power unit of the Armenian NPP was interrupted as result of accident on high-voltage power line. The accident cause on the power line was ice. It was formed as a result of frosty weather. There were no power outages;

3) in January 2017 in Japan a construction crane used for repair work at the Takahama NPP fell from strong wind on the second power unit and the spent nuclear fuel pool. The crane damaged part of outer wall and roof of the pool;

4) in February 2017 as a result of an explosion at the French nuclear power plant Flamanville, five workers were poisoned. The reactor reacted in operation was immediately shut down, although the explosion occurred outside the scope of nuclear fuel facilities;

5) in July 2018 in the city of Chernavode (Romania) there was an automatic disconnection from the National Energy System of the first power unit of the Romanian NPP. However, this sudden shutdown of the reactor did not affect the population, the station staff and the environment, and was most likely caused by an erroneous signal;

6) in July 2018 in Belgium at the Tihange NPP due electromechanical damage there was an emergency shutdown of the second reactor. The failure occurred due to problems with connection to the high-voltage network;

7) in September 2018 in Japan on the island of Hokkaido there was an emergency due to an earthquake. There was failure in operation of the main energy source that feeds pools cooling system with used nuclear fuel at the Tomari NPP. There was no radiation leakage;

8 ) in October 2018 in the west of Finland the first power unit of the Olkiluoto NPP of the company-operator Teollisuuden voima was disconnected due to turbine failure. It caused disconnection from the Finnish state grid. This incident did not affect nuclear safety of the facility.

9) in April 2019 a fire broke out at Rivne NPP in the evening. Due to damage to the 7AT communication transformer with its subsequent combustion the first 330 $\mathrm{kV}$ bus system was disconnected and the №3 power unit was disconnected accordingly. Rescuers put out the fire around 10 p.m. This event was classified as "zero" according to the international scale of events at the INES nuclear facilities;

10) in January 2020 an emergency situation occurred at the Ikata NPP (Japan). At the third NPP power unit, one of the 48 control cassettes was accidentally removed during withdrawal of fuel assemblies and no radiation leakage occurred.

The source of data on dangerous events that occurred at Ukrainian NPPs are reports on the investigation of violations in their work and the information system "Violations in the work of nuclear power plants". Information reports on violations in the operation of Ukrainian NPPs during 2020 are presented on the website of the State Scientific Technical Center for Nuclear and Radiation Safety [41]. Fig. 2 shows number of violations in operation of Ukrainian NPPs during 2005-2019. Distribution of violations in operation of NPPs that occurred during 2019 by sites of Ukrainian NPPs is as follows: at Zaporizhzhya NPP - 6 violations; at Rivne NPP - 5 violations; at Khmelnytska NPP - 1 violation; at the South-Ukraine NPP - 1 violation [40]. There is a deviation from the normal mode of operation (abnormal event) during a failure in the operation of the NPP as stated in [43]. It may be caused by equipment failure, external influences, personnel errors or deficiencies in the procedure. 34 anomalous events were recorded in 2017, during the investigation of violations and deviations in the operation of Ukrainian NPP power units. Their distribution was: mechanical damage - 12 events; faults in the electrical part - 12 events; staff errors - 6 events; not defined - 2 events; faults in control and measuring systems - 1 event; hydraulic influences - 1 event. In the event of accidents at nuclear power plants in Ukraine number of NNEGC "Energoatom" guidelines are used to ensure safety and protection of population and territories from emergencies, to prevent their occurrence and to effectively eliminate the consequences.

Significant part (54\%) of all violations in the operation of Ukrainian NPPs that occurred during 2019 led to reactor shutdown, unloading or disconnection of the unit from the network (categories P05, P08). It reduces residual design life of equipment important for safety, and reducing regulated number of load cycles of the reactor unit. Another $16 \%$ are violations (categories P03, P10) associated with the inoperability of security channels [40].

Also number and quality of cyber attacks on critical infrastructure are currently increasing. As an example Stuxnet is a computer worm that was created to attack Iran's nuclear facilities and was discovered in June 2010 [64]. Using operating system vulnerabilities and the human factor, Stuxnet successfully hit more than 1,000 centrifuges at a uranium enrichment plant. Also in December 2014 a cyber attack was carried out on automated workplaces of nuclear power plant operators in South Korea [65]. As part of these cyberattacks thousands of phishing emails with malicious code were sent and valuable information was stolen. In autumn 2019 systems of the Kudankulam NPP station (the most powerful NPP in India) were attacked with one of the versions of the virus known as DTrack [66]. This malware was specifically compiled for distribution and operation in the 
power plant network. Dtrack infected only the administrative network and did not reach the critical internal network used to control the plant's nuclear reactors. Thus threat of terrorist and cyber-terrorist acts against nuclear power plants exists and acquires new features every day.

We agree with the authors of the publication [7] who emphasize that human factor, inattention, equipment failure, natural disasters and fatal coincidence can lead to an accident at a nuclear power plant with human casualties.

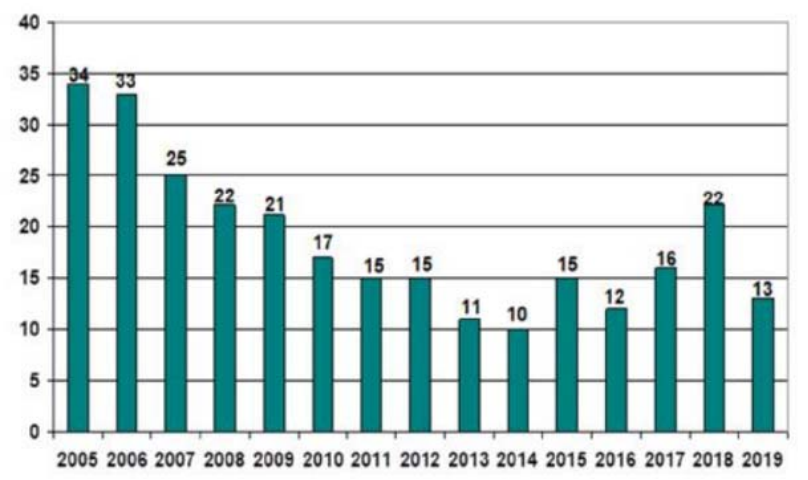

Fig. 2. Statistics on violations number in the operation of Ukrainian NPPs for 2005-2019 [40].

It should also be noted that Ukraine is still at the very beginning of creating of modern integrated system for responding to safety incidents and crises related to critical infrastructure. Thus, only in 2016 in the national legislation of Ukraine appeared definition of basic term for this area "critical infrastructure" [67].

NPP operation experience shows that accidents and incidents causes are somehow related to people (human factor) - with their attitude to safety issues. Therefore, NPP management focus is human resources, management style/methods, socio-psychological climate in production teams. NNEGC "Energoatom" is involved in process of safety culture forming in all staff beginning from the highest administrative level. There are permanent safety culture committees at the NPP. These are collegial bodies that coordinate NPP units activities in terms of maintaining and raising the level of safety culture [6].

Currently number of special measures are developed to prevent and eliminate accidents at Ukrainian NPPs, an Emergency Response System was created, special instructional materials were prepared, and so on. For example, Rivne NPP Emergency Response System is an interconnected set of human and technical resources, organizational and technical activities carried out by NPP personnel under the direction of the administration. It is done in order to prevent or mitigate impact of accidents or emergencies on personnel, the public and the environment. Main tasks of Rivne NPP emergency response system are following: ensuring readiness for localization and liquidation of accidents and other emergencies at NPPs and liquidation of their consequences; response to accidents and emergencies; implementation of measures to protect the station staff, population and environment; main tasks of the Rivne NPP emergency response system for population and environment protection; enhanced monitoring of radiation indicators of environment and irradiation of population; forecast of radiation doses of population in observation area; informing central and local executive bodies and local self-government bodies about monitoring results and forecasting of radiation doses to population; providing recommendations to central and local executive bodies and local self-government bodies on countermeasures to protect population [68].

Various measures are constantly taken to prevent emergencies at nuclear power plants. For example, mandatory psychological testing is important during employment and transfer to other positions for NPP personnel. It is stated in requirements for employeeson official websites [69]. Competition for various positions is held in following stages: 1) documents receipt; 2) psychological testing; 3) professional testing; 4) interview with commission.

The official website of Rivne NPP [70] contains a lot of information about the operation of the station and the work of staff. One of site publications states that person is a key factor in any production and its safety and enterprise production indicators directly depend on personnel working. The Rivne NPP staff development department has been operating for a year to improve the enterprise management system, improve and coordinate work with staff, assist managers in working with staff, monitor the socio-psychological climate in the power plant and improve safety culture through staff development. The personnel development department is entrusted with such important and urgent tasks as selection of personnel for certain positions, identification and development of leadership potential, organization of planning of work with personnel in departments, training of managers in management psychology and assistance in working with personnel. Specialists of the human factor management group of the personnel development department carry out number of important works with the operational personnel of the power plant on a regular basis. In addition to standard procedures, such as selection for positions at recruitment and transfer, routine surveys of working operational staff are carried out to ensure that position is suitable for professionally important qualities of the operational staff. Psychocorrectional trainings, sessions of psychoemotional unloading in a specially equipped room are carried out for employees of operational services, in case of reduction of their professionally important psychophysiological qualities. Classes are periodically held on the following topics to maintain the qualifications of operational personnel: safety culture, communication, methods of error prevention, conflict resolution, behavior in emergency situations and others. Another urgent task for the department specialists is psychological support operational personnel training on full-scale simulator [71]. Seminars for managers and their reserve on business psychology are very popular communication, leadership, teamwork and time management. For nuclear energy, openness and trust between staff and managers is important, because favorable psychological atmosphere in the team creates conditions for identifying hidden shortcomings that can be a prerequisite for serious incidents. Another important part of the specialists' activities of the personnel 
development department is socio-psychological climate in the NPP monitoring through anonymous questionnaires, surveys, and interviews in the units. Twice a year the specialists organize meeting of the Safety Culture Council at the Rivne NPP chaired by the General Director. Its main goal is to define strategy, plan, monitor and coordinate actions aimed at developing a safety culture. In March 2020 the survey was conducted on the Rivne NPP as whole to determine level of development of safety culture. The survey results confirmed high level of development of safety culture at the enterprise. The administration of Rivne NPP realizes that motivated, professional employees are valuable resource of organization. Staff needs constant careful work, improvement and expansion of professional knowledge and formation of safety and production culture, because safety issue at all levels of NPP activity is a priority [70].

Interview with the Rivne NPP CEO [72] highlighted main issues concern public and the power plant staff today. "Today nuclear power plant is not only the largest energy company in the region, but also local largest employer and taxpayer. Life of its entire satellite city practically depends on Rivne NPP. The main thing is that staff and equipment work reliably and safely. During pandemic we spend a lot of money to purchase personal protective equipment for staff, tests, preventive measures, including the isolation of operational staff - hotel accommodation, meals. In addition, mode of operation of our company changed significantly. It applies to certain activities such as staff training, detours, including work performed by contractors, because we have limited access to industrial site of involved employees. For some time, all this is justified and will not affect production. In the event of pandemic continuation it will certainly negatively affect work of the team" [72].

In 2020 due to pandemic COVID-19 another important factor emerged that could lead to emergencies at existing NPPs because personnel also had cases of COVID-19 and such cases continue. The NPP management takes many different measures to preserve employees health, comply with quarantine restrictions, daily check of body temperature of personnel, issue personal protective equipment, transfer to remote work of individual employees, etc. However, NPPs are enterprises where it is not possible to transfer large number of employees to remote work because many work processes have to be performed by people. Therefore, there is a risk with critical number of station employees who have to be at work every day or in shifts. Table 1 presents data on personnel number at Ukrainian NPPs for November 2020. Of course employees' number is not accurate due to monthly changes.

Table 1. Data on personnel number at Ukrainian NPPs for November 2020.

\begin{tabular}{|c|c|}
\hline NPP & Number \\
\hline Zaporizhzhya NPP & More than 11000 workers \\
\hline South-Ukraine NPP & More than 8500 workers \\
\hline Rivne NPP & More than 7800 workers \\
\hline Khmelnytska NPP & More than 5000 workers \\
\hline Total & 32300 workers \\
\hline South-Ukraine NPP & More than 8500 workers \\
\hline
\end{tabular}

Fig. 3 shows location of nuclear power plants in Ukraine with their characteristics according to [73]. According to Fig. 2 Zaporizhzhya NPP has 6 VVER-1000 units and it is the largest in terms of staff (over 11,000 employees), South-Ukraine NPP has 3 units VVER-1000 and it is the second largest in terms of staff (over 8500 employees), Rivne NPP has 2 power units VVER-1000 and 2 power units VVER-440 and it is the third in terms of staff (over 7800 employees) and Khmelnytska NPP has 3 power units VVER-1000 and is the smallest (over 5000 employees) in terms of staff among operating stations.

Fig. 4 contains data [74] on the spread of COVID-19 coronavirus infection in Ukraine by region for of December 23, 2020. It shows number of already confirmed cases and the total number of COVID-19 patients in each region since the epidemic beginning. Also, the total number of people infected with COVID-19 is 989,642 , among them 615,660 are recovered, and there are 17,172 deaths. If we compare Figures 4 and 5 we can assume that at the moment the staff of Rivne NPP and Khmelnitsky NPP is in high danger zone. They therefore need special safety measures, social and psychological support because they are located in the areas with large number of cases of COVID-19. It can not be NPP employees, but for example their relatives, close friends, neighbours and others. Therefore, it is necessary to pay attention not only to physical condition of employees, but also to the psychological health of staff.

\subsection{Measures and recommendations for social and psychological support of NPP personnel}

The world community faced uncertainty period due to COVID-19 pandemic. In many countries, the pandemic threatens not only human life but also economic, social and other spheres of public life [5]. Social consequences of the pandemic are: breaking family ties, disrupting social networks, destroying community structure and resources, declining trust, increasing gender-based violence, and more. Psychological consequences of emergencies are their impact on different levels of mental functioning - emotional state, behaviour, relationships. They can be related to: problems that existed before (mental disorders, alcohol or other chemical abuse); problems that arisen a result of emergency (nonpathological distress, mental disorders: depression, posttraumatic stress disorder (PTSD), anxiety disorders, adaptation disorders) [4]. Mankind found itself in situation of change and uncertainty for which it was not ready. The pandemic provokes increased anxiety, distress and other reactive states in people. Also, one of the specific features that causes socio-psychological problems is quarantine restrictions and inability to contact directly in usual circle of social interaction [5]. Each person's response to emergencies is different because each person has different resources and opportunities to recover [4]. Therefore, wide range of citizens began to need psychoprophylaxis, crisis counseling and sociopsychological support.

Currently, the pandemic regime was introduced in the world. This period is characterized by alarming 
information content, increased psychological pressure due to unfavorable epidemiological situation. Symptoms of frustration, hopelessness, fear, anticipation of threat, loneliness, social isolation and alienation, sleep disturbances and nightmares, irritability and outbursts of anger are just a few of PTSD symptoms seen in people in different countries. Such manifestations are observed in the population of Ukraine. The work [5] identified sociopsychological consequences of the pandemic for individual:
- loss of basic sense of safety;

- increase in anxiety and fear (for example, get sick, lose your ability to work);

- new living and working conditions (remote work in online format);

- mixing social roles (for example, home office, when you need to combine several roles of wife-motherspecialist/husband-father-worker, etc.).

Fig. 3. NPP placement in Ukraine [73].
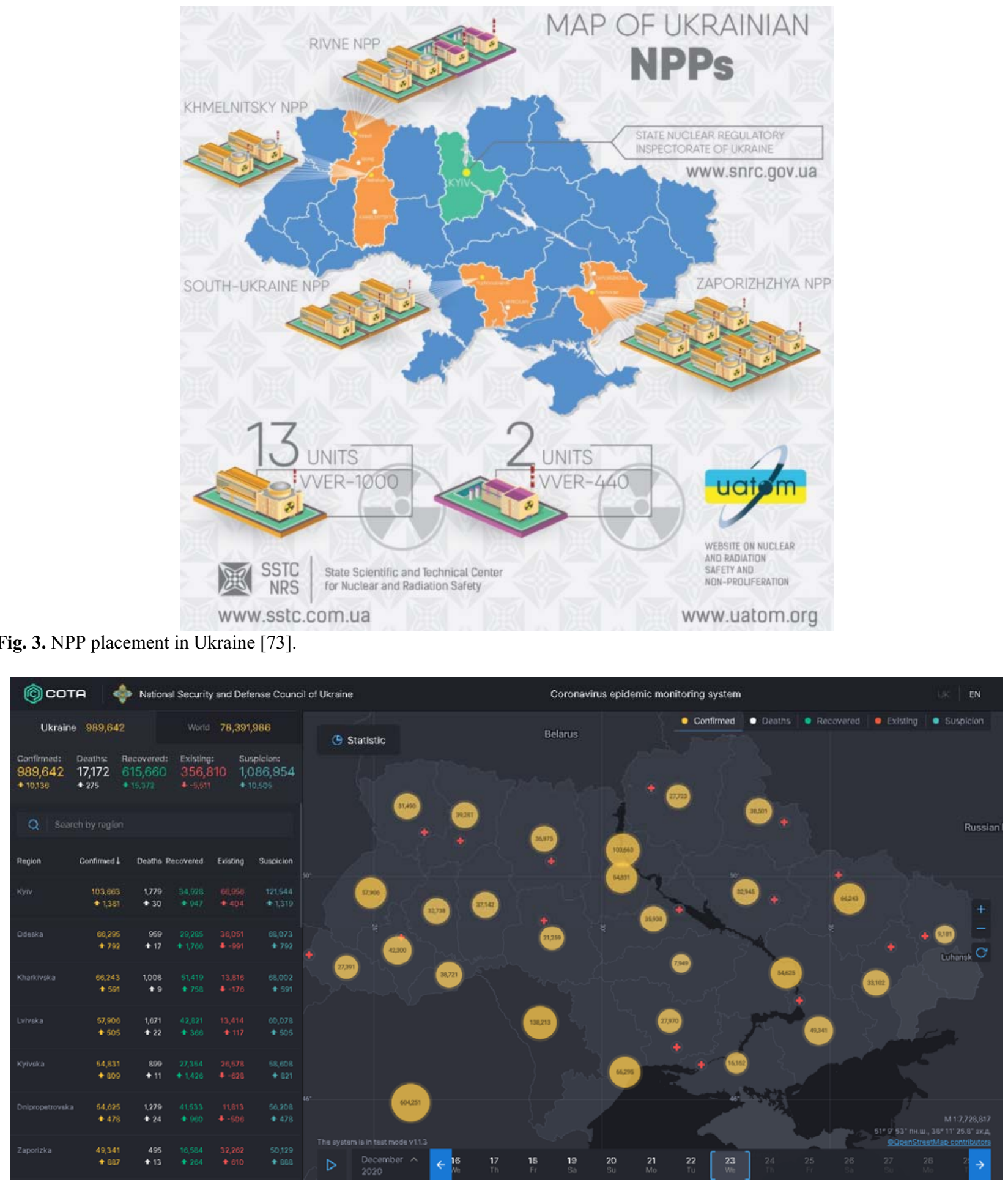

Fig. 4. Statistical data on COVID-19 spread in Ukraine by the regions [74]. 
In 2007 the United Nations together with the governments of various countries adopted the "Guide to Mental Health and Psychosocial Support in Emergencies". The document states that the main goal is to provide humanitarian actors and communities with strategy to plan, implement and coordinate system of minimum multisectoral response to protect and improve mental health and psychosocial well-being of population in emergency midst [4].

The article 38 "Psychological protection of the population" states [56]: 1) measures of psychological protection of population are aimed to reduce and neutralize negative mental states and reactions among population in case of threats and emergencies and include: planning activities related to psychological protection; timely application of licensed and permitted in Ukraine informational, psychoprophylactic and psychocorrectional methods of influencing individual; identification with help of psychological methods of factors that contribute to emergence of sociopsychological tension; use of modern psychological technologies to neutralize negative impact of emergency factors on population; implementation of other measures of psychological protection depending on current situation; 2) organization and implementation of psychological protection measures of population are entrusted to central body of executive power which ensures formation and implementation of state policy in the field of civil protection.

The publication [5] identifies current research problems in the field of health psychology of personnel of organizations and enterprises in the pandemic COVID-19:

1) in organizational psychology: essence of psychological health and well-being of staff in the organization in "normal" conditions and in the pandemic COVID-19; psychological features of personnel activity in self-isolation conditions; ensuring Work Life Balance in crisis situations; psychology of change management in organization in the context of the COVID-19 pandemic (adaptation to change, introduction of new forms of work, teamwork, etc.); new forms of personnel communication in organizations during the COVID-19 pandemic, new manifestations of conflicts in the organization during the COVID-19 pandemic; prevention of occupational stress and burnout in representatives of risky occupations (military, doctors, firefighters, etc.) and in other occupational groups of personnel during the COVID-19 pandemic; psychology of gradual exit of organizations from quarantine etc.

2) in the field of psychological assistance and psychological training of personnel in the organization: distance learning of personnel during the pandemic COVID-19: opportunities and limitations; psychological features of digital technology use, etc.

Also, psychologists-practitioners in [5] noted trends in client requests to psychologists and psychotherapists during COVID-19: a) existential issues: isolation, meaninglessness of life and what is happening (deprivation of meaning), suicidal thoughts, etc.; b) psycho-emotional states: fears (especially fear of death), anxiety, neurosis, stress, panic attacks, exacerbation of phobias, depression, impulsive-compulsive disorders; increased emotionality, exacerbation of neurotic states, etc.

Consider social system "NPP Staff" it should be noted that for NPPs of Ukraine such group can be on average 5000-10000 people - from worker to control panel operator or management of NPP. Subsystems are easily identified in this system: operational personnel, repair and maintenance personnel, seconded personnel, managers. Also, each subsystem is divided into shops, sections, changes according to NPP structure. Each of subsystems consists of tens or hundreds of elements (individuals) that form certain group (team) united by common goals and objectives. Each group performs specific (regulated) task, has its own hierarchy and living space. Of course, each individual has its own specific responsibilities but all are interdependent [62].

Decision on candidate's professional suitability for work at NPP is made by the commission on professional selection taking into account recommendations of the personnel department, incoming knowledge control, results of the interview with the structural unit head to which the candidate comes and conclusion of psychophysiological examination [6].

During the pandemic NPP personnel received an additional stress as work on critical infrastructure is considered to be quite complex and responsible.

Considering impact of negative stress on employees activities it is necessary to study conditions that contribute to optimization of their activities in extreme situations. An important factor in increasing psychological readiness ispresence of action plans in different types of extreme situations, their internal modeling and their activities in them. This not only increases psychological readiness but also helps to master new algorithms [47].

At present it is important for organizational psychologists and special departments to work with NPP personnel to diagnose mental health problems in organization during the COVID-19 pandemic and to provide appropriate psychological assistance to personnel. Such socio-psychological support can be implemented through webinars, psychological training, online and "regular" psychological counseling, etc.

Taking into account the above recommendations will create controlled situation of verbal support and jointly develop rational behavior and strategy to overcome situation and solve pressing psychological problems. Of course, all these global crisis processes require new approaches not only in individual psychological counseling but also in group of work and in creating psychological support for organizations staff. After all employees who are in state of anxiety lose concentration, perform tasks longer, make difficult decisions, become more conflicted, and so on [5].

Analysis of the NPP official websites showed that various measures for psychological support were developed for station staff: 1) people who undergo psychological testing are accepted to work at station as NPP is a potentially dangerous object; 2) various trainings are conducted (development of leadership qualities, conflict prevention, development of stress resilience, teamwork, etc.); 3) special rooms of rest and relaxation are created. 
Psychologists working at NPPs can use special questionnaire to establish referral criteria in event of serious mental problems occurring in staff. In [4] it was emphasized that stress can cause various reactions, including psychological (can be manifested in certain emotions, thoughts, behavior), physical (certain bodily manifestations) and others. Need for referral to receive the necessary services becomes clear depending on severity of these symptoms, their duration and the impact on daily functioning.

As a result of analysis of the scientific literature $[4,5$, 46-52] it was determined that there are certain types of mobile applications for mental health. People can use them on their own without psychologists help. They contain various methods and recommendations of psychologists, social workers for psychological support of the affected population.

Early provision of information and training to cope with stress can prevent dangerous consequences of psychotrauma. Educational orientation of mobile applications can be key in providing psychological assistance. Because it is very important to get clear and orderly information about their condition and understand what to do next for victim of stressful events. Studying typical consequences of psychotrauma helps to better understand one's own reactions to stress, and knowledge of one's resources (constructive coping strategies) provides sense of control over these reactions. It is important to explain necessary information about mental health, psychological problems and their consequences to people. It contains the following elements: information transfer, emotional relaxation, explanation and application, self-help training [51].

Varieties of electronic services that can be used to process traumatic experiences are quite wide: informing, diagnosing, monitoring, support, reminders, communication. Mobile applications with such functions can be used at any stage of socio-psychological work in the pandemic and psychotrauma. Specialized applications contain necessary information suitable for processing various experiences (increased anxiety, avoidance of social contacts, conversations about traumatic experiences, symptoms of intrusions or hyperexcitability, etc.). Obtaining specific information can prevent prevalence of post-stress disorders and contribute to spread of good practices for maintaining mental health [51].

Mental health mobile applications are applications to support mental health. Most of them are aimed primarily at promoting of healthy lifestyle, self-assessment, selfmonitoring, prevention, as well as step-by-step treatment of various disorders. Such functions can be used by person both independently and as material to provide psychologist or psychotherapist. Effectiveness of such electronic interventions in depression, psychosis, increased anxiety was proven. Apps for tracking mood swings, coping with stress, sleep disorders and eating habits are effective and popular. For example, the PTSD Coach supplement is used to prevent and overcome the symptoms of PTSD as an extreme manifestation of psychotrauma. Bust PTSD, Breathe2Relax, Beat PTSD, Tactical Breather applications are aimed to improve self- healing skills through meditation and concentration on breathing. You can effectively monitor mood changes with the T2 Mood Tracker monitoring application. Provider Resilience, LifeArmor, AZNG Be Resilient Program, Develop Your Resilience applications offer useful psychological skills. And the PFA Mobile and Care4Caregiver applications are designed specifically for professionals as guides to working with victims [50]. Examples of mobile applications are presented in Fig. 5.

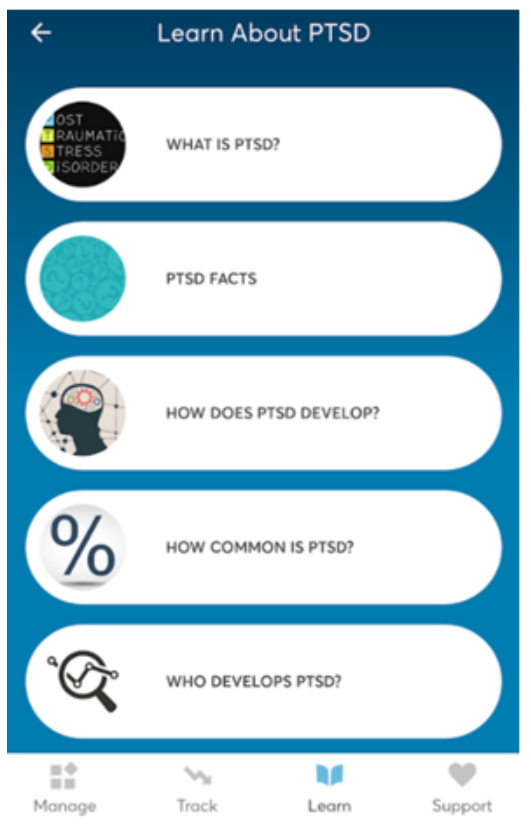

a)

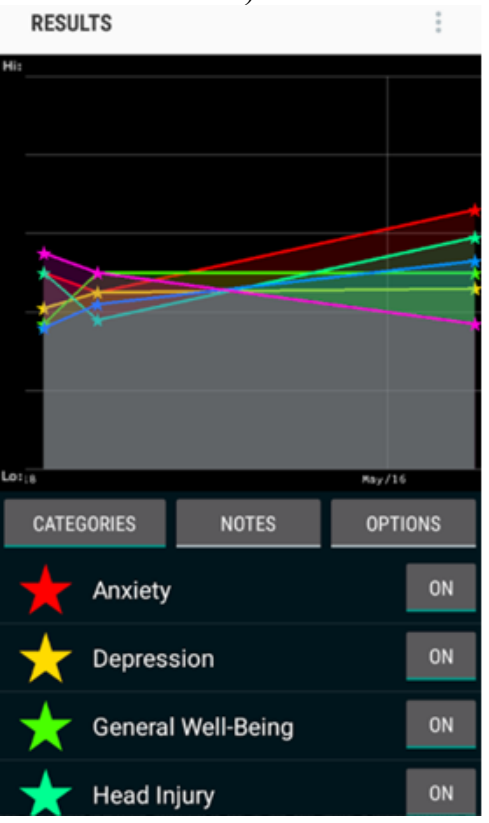

b)

Fig. 5. Examples of mobile applications work: PTSD Coach (a) and T2 Mood Tracker (b).

The service "Mobile psychological assistance" is presented on the site [54]. The program allows user to assess its own condition in such categories as sleep quality, depression and PTSD, as well as contains text materials sorted in menu and notes on symptoms of PTSD; anger management; depression control; alcohol 
and drug addiction; stress; relations with relatives; psychological resilience. There are also tools to assess your own condition; videos about PTSD; as well as list of psychological care services. The application "PFA Mobile Ukraine" contains recommendations for providing first psychological assistance to both victim himself after receiving a trauma and those who find themselves next to such a person - colleagues and relatives. However, it is important to remember that use of psychological mobile application cannot replace deepseated methods of psychotherapy. So it should be considered as primary psychological assistance of individual. Advantages of using specialized applications are following [50]:

- it saves time that would be spent for specific information or specialist searching;

- it overcomes barrier of space and resource base;

- it can be used on different devices by linking to virtual account;

- it is free (in the vast majority) or has much lower cost than individual meetings with specialist;

- it to the user, providing his autonomy;

- it is suitable for those who are wary of contact or have prejudices against psychologists;

- it corresponds to specific psychological problem and is aimed at its solution;

- it allows you to track changes in the state, which encourages the user to continue working, cultivates in him a commitment to self-help and help.

\section{Conclusions}

In 2020 COVID-19 led to the pandemic and caused an emergency worldwide, threatening lives and population health with large number of deaths and injuries. Also, during the pandemic there was (and continues to be) a violation of normal living conditions, significant material damage to economies of different countries. Quarantine restrictions affected social, educational, cultural and spiritual spheres of society. There is urgent threat to operation of critical infrastructure because the pandemic led to large numbers of hospitalized people or being isolated and treated at home. Operation of critical infrastructure facilities is strategic importance for proper functioning of any country. It includes energy, chemical, transport and other enterprises, and in particular nuclear power plants.

Scientists determined that threat of potentially dangerous situations remains and can cause radioactive and chemical contamination of the environment and harm the health of personnel and the public despite introduction of technologies and automated monitoring systems at nuclear power plants. Also one of the key means to ensure NPP safety operation and its further improvement is to take into account previous experience of operation and elimination of initial stage of emergencies. It includes accounting and analysis of disturbances in operation of stations, implementation of corrective measures to prevent violations. Analysis of violations statistics in operation of Ukrainian NPPs over the past few years shows that violations above the 1st class (anomaly) on the international INES scale have not occured at these power units. Indeed, in energy sector of Ukraine in recent years no threats were identified associated with emergencies risk due to equipment failures or extreme natural phenomena. However, there are additional risks associated with growing threats of nuclear terrorism, armed conflict in southeastern Ukraine and problems related to the COVID-19 pandemic (diseases of NPP personnel or their relatives). Therefore, problem of psychological health of NPP personnel during the pandemic is one of the relevant topics for research.

Currently, number of special measures were developed to prevent and eliminate accidents at Ukrainian NPPs, special instructional materials were prepared and the Emergency Response System was created. It is interconnected set of human and technical resources, organizational and technical measures or mitigating impact of accident or emergency on personnel, public and environment.

Also, psychological testing is mandatory for plant personnel during employment and transfer to other positions in order to prevent emergencies at NPPs. Various trainings (development of managerial qualities, conflict prevention, emotional burnout, etc.) are conducted and rooms for relaxation and rest are created.

Currently, extreme situations of activity are analyzed in three main aspects in psychological research: as features of situation itself, as a set of conditions of activity; as features of subject of activity in extreme situations, its readiness; as features of consequences of activity in difficult conditions of professional activity. Therefore, work of NPP personnel can be considered as a "set of operating conditions", i.e. work on potentially dangerous object. Ukraine is also implementing an international "Guide to Mental Health and Psychosocial Support in Emergencies". The terms "mental health" and "psychosocial support" mean measures aimed at protecting and promoting psychosocial well-being, as well as prevention and/or treatment of mental disorders.

Socio-psychological support is important to promote mental health during the COVID-19 pandemic especially for critical infrastructure workers. Stress associated with uncertainty and threat to health can have negative consequences for well-being and mental health of employees and can result in depression, emotional exhaustion, and anxiety.

Timely detection and appropriate work to restore mental health during the pandemic is an equally important area of work along with providing medical care to the population. Psychological mobile applications should be considered as economical way of primary care - proper psychological information of the population [51].

NPP is a potentially dangerous object, so, recommendations were prepared for social and psychological support of NPP personnel:

1) organize a system of informing staff about measures to prevent and reduce the risk of COVID infection; it in turn will help restore sense of safety and reduce anxiety level of employees;

2) conduct trainings or webinars on organizational issues online; it will discuss rules, advantages and difficulties faced by employees during the quarantine 
period, ways to overcome these difficulties, introduction of mentoring system;

3) organize team building, meetings, rituals online (for example, morning online meetings over cup of coffee to stabilize psycho-emotional state of employees);

4) carry out personnel screening procedure; if disorders of adaptation take place against background of more pronounced psychological trauma and depression it is necessary to refer to psychotherapist or psychiatrist;

5) carry out once every few months testing and interviewing staff;

6) create positive image and commitment to psychological counseling and seeking psychological help;

7) advise NPP employees to independently use specialized mobile applications for psychological support.

\section{References}

1. M.H. Shakil, Z.H. Munim, M. Tasnia, S. Sarowar, COVID-19 and the environment: A critical review and research agenda. Sci Total Environ. 745, 141022 (2020). doi:10.1016/j.scitotenv.2020.141022

2. J. Tao, Y. Ma, C. Luo, J. Huang, T. Zhang, F. Yin, Summary of the COVID-19 epidemic and estimating the effects of emergency responses in China. Scientific Reports, 11(1), 717 (2021).

3. S. Semerikov, S. Chukharev, S. Sakhno, A. Striuk, V. Osadchyi, V. Solovieva, T. Vakaliuk, P. Nechypurenko, O. Bondarenko, H. Danylchuk, Our sustainable coronavirus future. E3S Web Conf. 166, 00001 (2020).

4. N. Husak (ed.), Psychosocial support in emergency situations: a resilience approach (NaUKMA, Kyiv, 2017)

5. The impact of COVID-19 pandemic on staff mental health: problems and support technologies, in Abstracts of the XIV International scientific-practical online conference on organizational and economic psychology, Kyiv, Bila Tserkva, 21 May, 2020

6. Energoatom Non-Financial Report 2016 (2017), https://cutt.ly/0hwnMP3. Accessed 23 Dec 2020

7. Collection of developing projects developed within the framework of the Program of preparation of perspective personnel reserve of SE "Atomremontservice”, Slavutych, 2019.

8. L. Shkitsa, T. Yatsyshyn, M. Lyakh, O. Sydorenko, Innovative approaches to the formation of environmental safety at the objects of oil and gas production. IOP Conf. Ser.: Mater. Sci. Eng. 749, $012009 \quad$ (2020). doi:10.1088/1757$899 X / 749 / 1 / 012009$

9. Y. Balashevska, Y. Kyrylenko, O. Pecherytsia, I. Shevchenko, V. Bogorad, Harmonization of Methodological Approaches and Real Time Radiological Consequence Forecasting Tools. Nucl.
Radiat. Saf. 2(86), 20-26 doi:10.32918/nrs.2020.2(86).03

10. T. Yatsyshyn, L. Shkitsa, O. Popov, M. Liakh, Development of mathematical models of gas leakage and its propagation in atmospheric air at an emergency gas well gushing. Eastern-European Journal of Enterprise Technologies 5/10(101), (4959) 2019. doi:10.15587/1729-4061.2019.179097

11. M.L. Myrontsov, Electrometry effective inverse problem solving method, in Proceedings of the 19th International Conference Geoinformatics Theoretical and Applied Aspects 2020, vol. 2020, pp. 1-5. (2020). doi:10.3997/2214-4609.2020geo090

12. N. Pobihun, Y. Korobeinykova, O. Pobihun, I. Iuras, Ecological and monitoring studies of oil production territories and possibility of their use in recreation, in Proceedings of the XIII International Scientific Conference "Monitoring of Geological Processes and Ecological Condition of the Environment", vol. 2019, pp. 1-5. (2019). doi:10.3997/22144609.201903183

13. A. Zaporozhets, Overview of Quadrocopters for Energy and Ecological Monitoring, in Studies in Systems, Decision and Control, vol. 298, ed. by V. Babak, V. Isaienko, A. Zaporozhets (Springer, Cham, 2020), pp. 15-36. doi:10.1007/978-3-030-48583-2_2

14. A.O. Zaporozhets, V.V. Khaidurov, Mathematical Models of Inverse Problems for Finding the Main Characteristics of Air Pollution Sources. Water, Air, Soil Pollut. 231, 563 (2020). doi:10.1007/s11270020-04933-z

15. O. Mandryk, N. Moskalchuk L. Arkhypova, M. Prykhodk, O. Pobigun. Prospects of environmentally safe use of renewable energy sources in the sustainable tourism development of the Carpathian region of Ukraine. E3S Web Conf. 166, 04005 (2020). doi:10.1051/e3sconf/202016604005

16. M.L. Myrontsov, Multi-Probe Hardware for Electrometry of Oil and Gas Wells, Science and innovation $\quad \mathbf{1 4}(3), \quad 51-56 \quad$ (2018). doi:15407/scine14.03.051

17. O.M. Mandryk, N.R. Moskalchuk, L.M. Arkhypova, M.M. Pryhodko, O.V. Pobigun, Research quantitative indicators of the potential of solar energy in the Carpathian region of Ukraine. IOP Conf. Ser.: Mater. Sci. Eng. 749, $012033 \quad$ (2020). doi:10.1088/1757-899X/749/1/012033

18. A. Zaporozhets, V. Babak, V. Isaienko, K. Babikova, Analysis of the Air Pollution Monitoring System in Ukraine, in Studies in Systems, Decision and Control, vol. 298, ed. by V. Babak, V. Isaienko, A. Zaporozhets (Springer, Cham, 2020), pp. 85-110. doi:10.1007/978-3-030-48583-2_6

19. A.O. Zaporozhets, Methods and Means for the Control of the Fuel Combustion, in Studies in 
Systems, Decision and Control Systems, vol. 287 (Springer, Cham, 2020), pp. 1-33. doi:10.1007/9783-030-46299-4_1

20. L. Skitsa, T. Yatsyshyn, M. Liakh, O. Sydorenko, Ways to improve safety of a pumping-circulatory system of a drilling rig. Mining of Mineral Deposits 12(3), 71-79 (2018). doi:10.15407/mining12.03.071

21. L. Shkitsa, T. Yatsyshyn, M. Lyakh, O. Sydorenko, Means of atmospheric air pollution reduction during drilling wells. IOP Conf. Ser.: Mater. Sci. Eng. 144, 012009 (2016). doi:10.1088/1757$899 X / 144 / 1 / 012009$

22. O. Akimov, M. Karpa, C.V. Dubych, D. Zayats, N. Movmyga, N. Tverdokhliebova, Determination of requirements for protection of radio-electronic means of security management of particularly important state energy facilities from the destructive impact of electromagnetic, International Journal of Emerging Trends in Engineering Research, 8(9), 6214-6219 (2020)

23. O. Popov, A. Iatsyshyn, V. Kovach, V. Artemchuk, I. Kameneva, D. Taraduda, V. Sobyna, D. Sokolov, M. Dement, T. Yatsyshyn, Risk assessment for the population of Kyiv, Ukraine as a result of atmospheric air pollution. J. Health Pollut. 10, 200303 (2020). doi:10.5696/2156-961410.25.200303

24. M.L. Myrontsov, The method to solve the inverse problem of lateral logging sounding and lateral logging, in Proceedings of the XIII International Scientific Conference "Monitoring of Geological Processes and Ecological Condition of the Environment", vol. 2019, pp. 1-5. (2019). doi:10.3997/2214-4609.201903244

25. V. Gurieiev, O. Sanginova, Simulation and study of modes for full-scale mode simulator for Ukrainian energy systems, in Proceedings of the $2^{\text {nd }}$ International Conference on Intelligent Energy and Power Systems (IEPS'2016) (2016)

26. V. Gurieiev, O. Sanginova, Distributed simulation environment of modes for full-scale mode simulator for Ukrainian energy systems. Technical Electrodynamics 5, 67-69 (2016)

27. Yu. Zabulonov, O. Popov, V. Burtniak, A. Iatsyshyn, V. Kovach, A. Iatsyshyn, Innovative developments to solve major aspects of environmental and radiation safety of Ukraine, in Studies in Systems, Decision and Control (2021 in press)

28. A. Iatsyshyn, A. Iatsyshyn, V. Artemchuk, I. Kameneva, V. Kovach, O. Popov, Software tools for tasks of sustainable development of environmental problems: peculiarities of programming and implementation in the specialists' preparation. E3S Web Conf. 166, $01001 \quad$ (2020). doi:10.1051/e3sconf/202016601001
29. M.L. Myrontsov, (2012). A new method and program for multiprobe electric logging quantitative interpretation, in Proceedings of the 11th EAGE International Conference on Geoinformatics Theoretical and Applied Aspects, 00028 (2012).

30. O. Popov, A. Iatsyshyn, V. Kovach, V. Artemchuk, D. Taraduda, V. Sobyna, D. Sokolov, M. Dement, T. Yatsyshyn, I. Matvieieva, Analysis of possible causes of NPP emergencies to minimize risk of their occurrence, Nucl. Radiat. Saf. 81, 75-80 (2019). doi:10.32918/nrs.2019.1(81).13

31. IAEA Annual Report for 2017, Vienna, IAEA, https://www.iaea.org/sites/default/files/publications/ reports/2017/gc62-3.pdf. Accessed 23 Dec 2020

32. D. Taraduda, M. Dement, The approach to the quantitative assessment of the risk of occurrence of emergency situations associated with terrorist acts at radiation hazardous objects, Problems of emergencies 24, 126-133 (2016)

33. O. Popov, A. Iatsyshyn, V. Kovach, V. Artemchuk, D. Taraduda, V. Sobyna, D. Sokolov, M. Dement, T. Yatsyshyn, Conceptual Approaches for Development of Informational and Analytical Expert System for Assessing the NPP impact on the Environment. Nucl. Radiat. Saf. 79, 56-65 (2018). doi:10.32918/nrs.2018.3(79).09

34. S. Kis, L. Mosora, Y. Mosora, O. Yatsiuk, G. Malynovska, S. Pobihun, Personnel Certification as a Necessary Condition for Enterprise' Staff Development, Management Systems in Production Engineering 28(2), 121-126 (2020). doi:10.2478/mspe-2020-0018

35. L.A. Mikhailov, V.P. Solomin, Emergencies of a natural, technogenic and social nature and protection from them. (Piter, St. Petersburg 2008)

36. Order of the State Inspectorate for Nuclear Regulation of Ukraine dated 30.08.2017 №313 “On approval of the Requirements for periodic reassessment of safety of nuclear power plants" (2017), http://zakon.rada.gov.ua/laws/show/z115817. Accessed 23 Dec 2020

37. Main measures of the system of emergency preparedness and response of NNEGC "Energoatom" to accidents and emergencies at NPPs for the period up to 2020 (NNEGC "Energoatom", Kyiv, 2015)

38. The main provisions of the organization of the system of readiness and response of NNEGC "Energoatom" to accidents and emergencies at NPPs (NNEGC "Energoatom", Kyiv, 2018)

39. O. Pogosov, O. Derevianko, NPP Physical Protection and Information Security as Necessary Conditions for Reducing Nuclear and Radiation Accident Risks. Nucl. Radiat. Saf. 75, 50-55 (2017). doi: 10.32918/nrs.2017.3(75).09 
40. Report on the activities of the State Nuclear Regulatory Inspectorate of Ukraine for 2019, Kyiv, 2020, http://www.snrc.gov.ua/nuclear/doccatalog/ document?id=450225. Accessed 23 Dec 2020

41. Information reports on violations in the operation of NPPs during 2020, https://sstc.ua/informacijnipovidomlennya-pro-porushennya-v-roboti-aesprotyagom-2020-roku. Accessed 23 Dec 2020

42. O. Popov, A. Iatsyshyn, D. Sokolov, M. Dement, I. Neklonskyi, A. Yelizarov (2021) Application of Virtual and Augmented Reality at Nuclear Power Plants, in Studies in Systems, Decision and Control (2021 in press)

43. Annual report on the state of nuclear and radiation safety in Ukraine, https://snriu.gov.ua/dlyagromadskosti/shchorichna-dopovid-pro-stanyadernoyi-ta-radiacijnoyi-bezpeki-v-ukrayini. Accessed 23 Dec 2020

44. R.T. London, Is COVID-19 Leading to a Mental Illness Pandemic? https://www.medscape.com/ viewarticle/927849. Accessed 23 Dec 2020

45. V.E. Medvedev, Mental health in the context of COVID-19 pandemic: initial assessment, Clinical review for general practice 1, 22-28, (2020). doi: $10.47407 / \mathrm{kr} 2020.1 .1 .00004$

46. IPC Guide to Mental Health and Psychosocial Support in Emergencies (Universytetske vydavnytstvo PULSARY, Kyiv, 2017)

47. S.A. Mul, Dissertation, G.S. Kostyuk Institute of Psychology of NAPS of Ukraine, 2011

48. Basics of rehabilitation psychology: overcoming the consequences of crisis. Vol. 1, (Organization for Security and Co-operation in Europe, Kyiv, 2018)

49. Mental Health in Emergencies (World Health Organization, Geneva, 2003)

50. M.S. Dvornyk, Psychological mobile apps: the ways of psychotrauma overcoming, in Vseukrayins'ka naukovo-praktychna konferentsiya "Mediatravma $v$ umovakh informatsiynoyi viyny: psykholohichnyy ta pedahohichnyy aspekty" (2017)

51. M.S. Dvornyk, Smartphone applications usage in conditions of population's psychotraumatizaton, Information Technologies and Learning Tools 73(5), 236-248 (2019). doi:10.33407/itlt.v73i5.2760

52. K. Ly, J. Dahl, P. Carlbring, G. Andersson, Development and initial evaluation of a smartphone application based on acceptance and commitment therapy, SpringerPlus 1, 11 (2012). doi:10.1186/2193-1801-1-11

53. Mobile Phone Application PFA mobile Ukraine The first psychological aid, https://volonter.org/event/dodatok-dlya-
mob\%D1\%96lnih-telefon\%D1\%96v-pfa-mobileukraine---persha. Accessed 23 Dec 2020

54. Mobile psychological help, https://mobilementalhelp.tdmu.edu.ua. Accessed 23 Dec 2020

55. Z. Kowalczuk, M. Czubenko, T. Merta, Interpretation and modeling of emotions in the management of autonomous robots using a control paradigm based on a scheduling variable. Eng. Appl. Artif. Intell. 91, 103562 (2020). doi:10.1016/j.engappai.2020.103562

56. Verkhovna Rada of Ukraine, Code of Civil Protection of Ukraine, https://zakon.rada.gov.ua/laws/show/5403-17. Accessed 23 Dec 2020

57. DK 019: 2010. Emergency classifier (Derzhspozhyvstandart of Ukraine, Kyiv, 2010)

58. M. Somani, A.N. Srivastava, S.K. Gummadivalli, A. Sharma Indirect implications of COVID-19 towards sustainable environment: An investigation in Indian context. Bioresour. Technol. Rep. 11, 100491 (2020). doi:10.1016/j.biteb.2020.100491

59. Iu. Iuras, P. Raiter, Ya. Korobeinykova, L. Poberezhna, Methodology of actors analysis and modeling of the amounts of solid municipal waste generation within tourist destinations. Ecological Questions 31(2), 63-69 (2020). doi:10.12775/EQ.2020.014

60. I. Melnychuk, O. Savko, S. Pobihun, N. Havadzyn, The impact of a country's level of economic development on environmental safety. Procedia Environmental Science, Engineering and Management (2020 in pres)

61. P.I. Guchek, Dissertation, Kherson National Technical University, 2016

62. V.V. Behun et al., Safety culture in nuclear energy (NTUU «KPI», Kyiv, 2012)

63. The Information Channel on Nuclear and Radiological Events, https://www-news.iaea.org/ EventList.aspx. Accessed 23 Dec 2020

64. Another cyberattack by Stuxnet virus committed on Iran, https://www.bbc.com/russian/international/ 2012/12/121225_iran_stuxnet_attack. Accessed 23 Dec 2020

65. Cyberattacks on nuclear facilities, https://www.kommersant.ru/doc/3196397. Accessed 23 Dec 2020

66. NPCIL statement, https://ru.scribd.com/document/ 432687853/NPCIL-statement. Accessed 23 Dec 2020

67. O.M. Sukhodolya (eds.), Organizational and legal aspects of ensuring the security and sustainability of critical infrastructure of Ukraine (NISD, Kyiv, 2019) 
68. Rivne NPP emergency response system, https:/www.rnpp.rv.ua/emergency-response.html. Accessed 23 Dec 2020

69. Official website of South-Ukraine electric power producing complex, https://www.sunpp.mk.ua/ru /article/5545-uvaga-vidokremleniy-pidrozdilyuzhno-ukrayinska-aes-dp-naek-energoatomogoloshuie. Accessed 23 Dec 2020

70. Professionals are a valuable resource of Rivne NPP, https:/www.rnpp.rv.ua/professionalnyie-rabotnikiczennyij-resurs-rivnenskoj-aes.html. Accessed 23 Dec 2020

71. V. Gurieiev, Yu. Kutsan, A. Iatsyshyn, A. Iatsyshyn, V. Kovach, E. Lysenko, V. Artemchuk, O. Popov, Simulating Systems for Advanced Training and Professional Development of Energy Specialists in Power Sector. CEUR Workshop Proceedings 2732, 693-708 (2020). http://ceur-ws.org/Vol2732/20200693.pdf. Accessed 23 Dec 2020

72. For Rivne NPP employees it is psychologically difficult, when stopped the turbines, http://www.golos.com.ua/article/331179. Accessed 23 Dec 2020

73. Website on nuclear and radiation safety and nonproliferation, https://www.uatom.org/en/generalinformation. Accessed 23 Dec 2020

74. National Security and Defense Council of Ukraine, Coronavirus epidemic monitoring system https://covid19.rnbo.gov.ua. Accessed 23 Dec 2020 